\title{
Metabolic syndrome: maladaptation to a modern world
}

\author{
Terence J Wilkin MD FRCP Linda D Voss PhD
}

J R Soc Med 2004;97:511-520

For the public, obesity is largely a cosmetic issue. For the doctor, it underlies disturbances of lipid and glucose metabolism that are posing one of the greatest threats to health the world has known. Diabetes, cardiovascular disease, cancers and anovulation are the principal manifestations. Insulin resistance, consequent upon obesity, causes them and metabolic syndrome is the term used to describe them. Metabolic syndrome results from the maladaptation to overnutrition of genes selected to survive undernutrition. Obesity is a disease - a classic interaction between genes and a changed environment. This review attempts to give the metabolic syndrome perspective and to explain its impact on modern medicine.

\section{OBESITY IS AFFECTING THE WHOLE OF SOCIETY, NOT JUST A SECTOR OF IT}

Metabolic syndrome, referred to variously as insulin resistance syndrome or syndrome $\mathrm{X}$, represents a conjunction of several metabolic disturbances and is very much a product of our time. ${ }^{1}$ It is clearly associated with obesity and, insofar as it seldom occurs in people of low body mass and can be improved by weight loss, may well be caused by obesity. Data from around the industrialized world suggest that obesity rates have tripled in a generation, ${ }^{2}$ so that obesity and its likely causes are an appropriate place to start in any consideration of the metabolic syndrome.

The upward shift in body mass of industrialized societies over the past 25 years has been dramatic. ${ }^{3}$ The median body mass index (BMI) of the UK population in the 1970s was around 23, meaning that half the adult population just 30 years ago had a BMI below 23. An important question for health managers is whether the fat alone have become fatter, or the population as a whole. ${ }^{4}$ In the former case, intervention might reasonably be focused on the heaviest $20 \%$, with little fear that the rest would catch up. If, on the other hand, the whole population were gaining weight, public health strategists would face a quite different problem. Even if a policy successfully helped the heaviest to lose weight, their place would be taken by others. One approach to answering the question involves comparison of

Department of Endocrinology \& Metabolism, Peninsula Medical School (Plymouth campus), Level 7, Derriford Hospital, Plymouth PL6 8DH, UK

Correspondence to: Prof TJ Wilkin

e-mail t.wilkin@pms.ac.uk

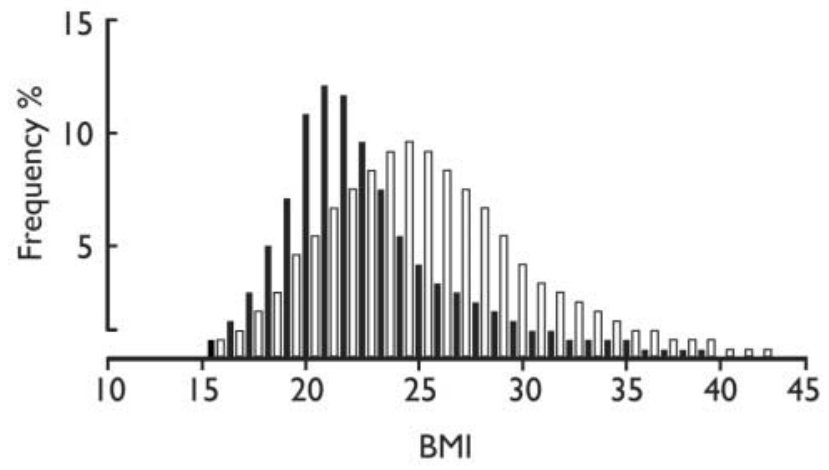

Figure 1 The shift in distribution of BMI of UK adults between the 1970s (black) and the 1990s (open).

Both the median and the mean have moved, suggesting that the whole of society is involved. Modified from ref. 3

the mean and median BMI over time. Lack of change in the median, while the mean increased, would suggest that only those of already high BMI were gaining weight, whereas movement of the median with the mean would indicate that the population as a whole was affected. The data are clear ${ }^{3}$ (Figure 1). The median BMI of the UK population by the late 1990s had risen from 23 to 26: over $60 \%$ of the adult population was now overweight by World Health Organization (WHO) standards. The median BMI of UK adults, which a generation ago was little different from that in the 19th century when Quetelet first proposed the BMI as a measure of fatness, ${ }^{4}$ now announces an epidemic of obesity.

\section{OBESITY IS A TRUE DISEASE INVOLVING GENES AND ENVIRONMENT}

Why should this transformation have occurred? A generation is less than a second on the scale of evolutionary time, so genetic change is unlikely to be responsible for such a rapid emergence of obesity. Change in environment is the more likely cause. It is reasonable to assume that mankind evolved on limited nutrition. For huntergatherers, excess would have been the exception. With limited food availability as a survival pressure, Darwinians would argue that survivors selectively carried genes for efficient storage of excess calories as fat. The advantage of being able to create energy stores is still evident in some preindustrialized populations, where seasonal availability of food is still associated with striking variation in body weight — and survival. ${ }^{5}$ 
Mankind as a whole entered the 20th century well adapted to privation, but the people of industrialized and industrializing nations were about to encounter an environmental change of a speed hitherto unmatched in evolutionary history. The turning point was probably the Second World War, with the rapidly rising prosperity of the 'westernized' nations that followed it. The mass ownership of personal transport, processing of food, consumption of carbonated sodas and increasingly sedentary occupations - a process dubbed 'coca-colonization' by Paul Zimmet $^{6}$ - have together conspired to achieve an unprecedented change in environment over a very short period. 'Progress' has made energy dense foods available to the masses at low cost and with minimum effort. The result was predictable but not predicted - an effect on society more devastating yet than the Medical Nemesis envisaged in the 1960 s by Ivan Illich. ${ }^{7}$ Equipped with genes ideally suited to - and expressly selected for - the storage of fat, modern man now inhabits a land of plenty. Worse still, we do not possess genes to control obesity, because weight excess was never until now a pressure on survival. Fatness in the 21 st century may not reflect the gluttony about which society has been so judgmental since Shakespeare's caricature of Sir John Falstaff, ${ }^{8}$ but rather a genotype for evolutionary survival wholly maladapted to its new environment.

Everything points to excess weight gain as a societal disorder and not the preserve of a few. BMI is a continuum and obesity is merely a category assigned to a particular BMI, which more and more of the population are reaching. Given this perspective, society and its medical profession may need to revise their view of the fat as feckless, and understand that obesity is a disease in the truest sense- a classic interaction between nature and nurture, susceptibility and risk, genes and environment. We need to think anew about environmental engineering for obesity, in much the same way as we have with smoking. Change will come with concern, but concern only with awareness. Awareness means education, but our understanding of the metabolic syndrome and what underlies it has emerged so recently that even the medical profession remains in large part unaware. Metabolic syndrome is fast becoming the industrialized world's primary cause of morbidity and mortality, outstripping infection, accidents and smokingrelated diseases. The WHO now views overnutritionnot undernutrition - as the principal cause of global malnutrition.

While the industrialized world is already trying to cope, metabolic syndrome presents an even greater threat to industrializing nations because the time-scale over which their life-styles have been 'westernized' is that much shorter and the maladaptation that much greater.

\section{OBESITY IS LARGELY RESPONSIBLE FOR INSULIN RESISTANCE}

As mentioned earlier, the public perceives obesity mainly as a cosmetic issue, and this may explain why most of those who attend weight management clinics are female. For doctors, it is a metabolic issue. Some researchers express concern that obesity also has important psychological effects, but there is little evidence that this is the case. Most of the data on this matter come from weight management clinics, where referral bias is a major confounder. Population studies suggest that weight excess has limited impact on personal wellbeing. ${ }^{9}$ In metabolic terms, however, a BMI of 25 (WHO definition of overweight, currently involving around $60 \%$ of young UK females and $70 \%$ of males) already portends a risk of type 2 diabetes five times that of BMI 22 or less, and a BMI of 30 (currently 20\% young UK females and 22\% males) some 28 times greater. ${ }^{10,11}$ Diabetes is associated with a $2-4$ times excess risk of cardiac mortality. What is the connection between BMI, diabetes and cardiovascular disease?

Figure 2 illustrates the negative feedback loop that controls the concentration of blood sugar. Feedback loops are ubiquitous in nature and in engineering design. They are used to maintain the product they control (sodium, potassium, glucose) within narrow limits, whatever the perturbation. ${ }^{12}$ In the case of glucose, the islets release insulin, which controls the flux of glucose in and out of the tissues. The flux results in a concentration of blood glucose that modulates the release of insulin according to a setpoint. Several tissues respond to insulin, principal among them fat, liver and muscle. Since there are only two components in the loop, there are essentially only two things that can go wrong - either the islets or the tissues fail to function. Loss of islet function (strictly beta-cell function) is typified by type 1 diabetes in children, where the beta cell mass is destroyed by the immune system. The kinetic that follows is straightforward: the blood insulin level falls and, as a result, the blood glucose levels rise.

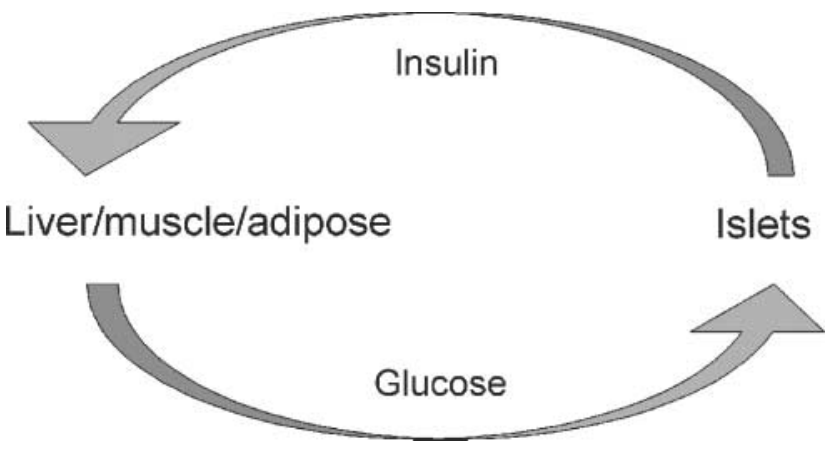

Figure 2 Schematic representation of the feedback loop controlling blood glucose.

If the islets fail (type 1 diabetes), glucose rises because insulin falls. If the tissues fail (type 2 diabetes), insulin rises because glucose rises 
Failure of the tissues, the other cause of control loop breakdown, is not due to anatomical loss as in type 1 diabetes but to functional loss. The tissues lose sensitivity to insulin - a phenomenon referred to as insulin resistance. The principal cause of insulin resistance is weight gain and the result, once blood sugar exceeds a threshold defined by the $\mathrm{WHO}$, is type 2 diabetes. The kinetics of loop function in type 2 diabetes, however, are quite different from those in type 1. The beta cells remain functional in insulin resistance, and respond to rising glucose by producing more insulin to overcome the resistance. For every quantum rise in body mass there is a rise in insulin resistance which weakens the loop's control over blood glucose. The glucose level rises slightly, but the beta cells are highly sensitive to any change and respond to a linear rise in glucose with a geometric rise in insulin. Of course, the islets cannot continue to respond to rising insulin resistance forever, and eventually their function saturates. At saturation, control of glucose is lost and diabetes ensues, but the levels of insulin are high, not low. They are considerably higher than those of a healthy person, but still not high enough to overcome the resistance that drives them. The crucial difference between type 2 diabetes and type 1 diabetes is hyperinsulinaemia.

\section{INSULIN RESISTANCE IS RESPONSIBLE FOR THE METABOLIC SYNDROME}

For decades, medicine saw the relationship between insulin and glucose as one confined to diabetes. In reality, the hyperinsulinaemia of insulin resistance is associated with a range of apparently disparate disturbances that include hyperglycaemia, hypercholesterolaemia (particularly LDL), hypertriglyceridaemia, hypertension, hyperviscosity (raised haematocrit), hypercoagulability (raised liver-derived plasminogen activator inhibitor-1) and hyperuricaemia. Each of these disturbances poses a cardiovascular risk in its own right, but together they are catastrophic to the macrovascular system. Although an understanding of the relationship between insulin resistance and metabolic disturbance is (appropriately) attributed to Reaven, with his seminal Banting lecture to the American Diabetes Association in 1988, ${ }^{1}$ Himsworth had noted 50 years earlier that some diabetic patients required increasing amounts of insulin and appeared to become increasingly insensitive or 'resistant'. ${ }^{13}$

The classic disturbances of the metabolic syndrome may be viewed as spokes of a metabolic wheel where insulin, which drives all of them, lies at the hub (Figure 3). Several important points emerge from this representation. First, the insulin levels that turn the wheel will not rise unless the glucose rises first. Glucose is the mediator of the high insulin levels and metabolic disturbances that characterize

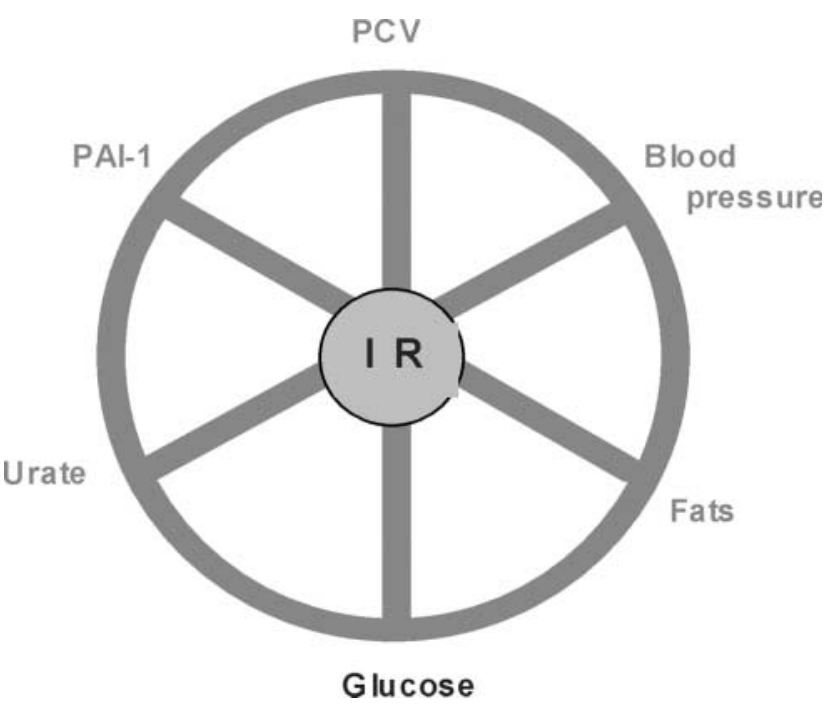

Figure 3 The metabolic wheel. Insulin resistance at its centre simultaneously drives a number of metabolic processes. The spokes are each linked through the hub, rather than to each other. PAI-1= plasminogen activator inhibitor 1; PCV=haematocrit

insulin resistance. However, such is the nature of the feedback loop that the insulin levels may be very high before glucose control (the connection between insulin and glucose) is lost. As a result, disturbances in the other spokes of the wheel may be far advanced before the patient becomes, by WHO definition, diabetic. It will also be clear that hypercholesterolaemia, hypertension etc, are not complications of diabetes but associations, mutually dependent on a common process. This is important, because the high glucose levels could be reduced clinically by raising the insulin levels still further (e.g. by use of a sulphonylurea), which might reduce $\mathrm{HbA} 1 \mathrm{C}$ but advance the other spokes of the metabolic wheel still further.

It is the combination of factors in the metabolic syndrome that so threatens cardiovascular health. People with isolated components are at lower risk, reflected in the scores used to guide the clinical use of cholesterol-lowering statins. ${ }^{14}$ The level of hypertriglyceridaemia cannot be used to stratify the risk of heart disease, but hypertriglyceridaemia in the presence of hypertension or hypercholesterolaemia makes the chance of a hyperinsulinaemic connection more likely. Bonora's analysis of the Bruneck study is highly instructive. ${ }^{15}$ Some $27 \%$ of the hypercholesterolaemic population of this town in the Dolomites had lone hypercholesterolaemia which was not associated with insulin resistance and posed little threat to cardiovascular health. Fasting triglycerides, on the other hand, were raised in the absence of other metabolic disturbances in only one case out of 75. In other words, hypertriglyceridaemia is a useful means of distinguishing syndromic hypercholesterolaemia (or hypertension or hyperandrogenaemia) from lone disturbances. Finally, the changes in lipids linked to weight excess, insulin resistance and the metabolic 
syndrome (high triglycerides, low HDL-cholesterol, small dense LDL-cholesterol) are not driven primarily by dietary intake. The key event in pathogenetic terms is probably resistance to insulin of adipose tissue hormone-sensitive lipase, which normally keeps a lid on lipolysis. ${ }^{16}$ The resultant release of free fatty acids into the blood is thought to generate systemic insulin resistance (by the cycle of competition between glucose and free fatty acids described by Philip Randle in the 1960s). The situation is analogous to glucose intolerance revealed by, but not caused by, high sugar intake. Both respond to weight loss and a fall in insulin resistance.

\section{CANCERS, METABOLIC DYSOVULATION AND PRE-ECLAMPSIA ARE ALSO COMPONENTS OF THE METABOLIC SYNDROME}

The metabolic syndrome has been referred to as the deadly quartet and even 'the deadly sextet'. ${ }^{17}$ It is now clear, however, that there are even more than six components to the insulin resistance syndrome. What was originally termed Stein-Leventhal syndrome, and subsequently polycystic ovary syndrome (PCOS), now appears to be a metabolic disorder of ovarian function driven by high insulin levels. ${ }^{18}$ Women derive their oestrogen by enzymatic conversion from androgen, and hyperinsulinaemia raises the production of androgen by the thecal cells of the ovary. ${ }^{19}$ The androgen/oestrogen imbalance blocks follicle development at an early stage, leading to anovulation, the cysts and the characteristic phenotype of hirsutism, acne and greasy skin. Since menstruation follows ovulation, women with PCOS are typically amenorrhoeic. The ovarian cysts that give the syndrome its name are coincidental, and pelvic ultrasound has given place to clinical and biochemical criteria for diagnosis. PCOS is probably better termed metabolic dysovulation, and is an early expression of insulin resistance. The waist circumference of such women is greater than that of fertile controls, and the risk of future diabetes and heart disease is increased. ${ }^{20}$ Metabolic dysovulation may now affect up to $6 \%$ of women of childbearing age, 22,23 a figure that represents more than twice the current overall prevalence of type 2 diabetes. If $6 \%$ of the female population is all of a sudden unable to ovulate, obesity and the metabolic syndrome it causes may have brought about in just 25 years the most rapid change to the gene pool in evolutionary time.

Hypertension has long been associated with insulin resistance. Recently, it has become clear that preeclampsia is commoner in women with metabolic dysovulation and is likewise associated with insulin resistance. ${ }^{24}$ Obesity and insulin resistance not only reduce fertility but also introduce specific risks when pregnancy is achieved.

The list of comorbidities associated with obesity is a long one, and an increasing number are linked to insulin resistance. Colorectal cancer was the first malignancy to be associated with insulin resistance, ${ }^{25}$ and others more recently reported include breast cancer ${ }^{26}$ and endometrial carcinoma ${ }^{27}$ - although here the tumorigenic factor may be the high oestrogen associated with metabolic dysovulation, rather than the insulin-like growth factors that are thought to operate in the other cancers. A most intriguing question is whether mood, in what is sometimes referred to as our 'low-mood society', may relate to insulin resistance. Notwithstanding the selection biases mentioned earlier, the issue has been taken seriously. ${ }^{28}$

\section{FAT DISTRIBUTION IS KEY TO INSULIN RESISTANCE}

Some 60 years ago, Professor Jean Vague from Marseille on the Mediterranean coast of France made a seminal observation. Those overweight patients attending his diabetic clinic whose fat distribution was upper abdominal (les pommes) were more susceptible to the morbidities of obesity than those whose fat was deposited in the buttocks and thighs (les poires). The observation was published first in French, and its dissemination was limited as a result, but when it appeared nine years later in the American Journal of Human Nutrition, ${ }^{29}$ the implications became clear to all. Upper abdominal obesity tends to be the male distribution, and gluteofemoral the female, though not exclusively. The distributions are largely hormone dependent, since prepubertal boys and girls of a given BMI show little difference in waist circumference or waist-hip ratio, whereas their parents clearly do. ${ }^{30}$ Furthermore, the

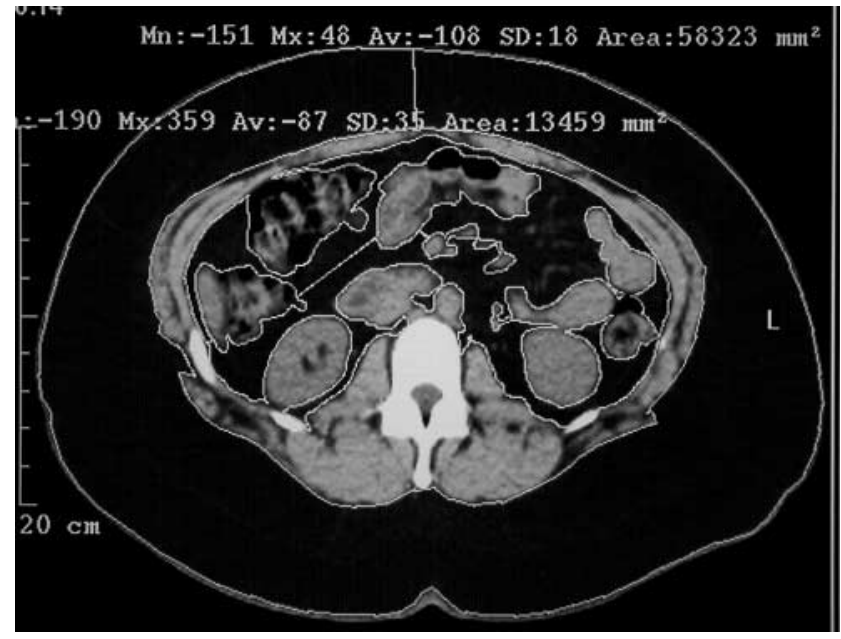

Figure 4 A transverse abdominal CT scan showing intraabdominal visceral fat in black (area $13459 \mathrm{~mm}^{2}$, metabolically harmful) but, in addition, a substantial amount of subcutaneous fat (area $5823 \mathrm{~mm}^{2}$, metabolically harmless) 
woman's lower distribution of fat tends to redistribute into the abdomen after the menopause, ${ }^{31}$ which may explain the relative cardiovascular protection that the female enjoys during her childbearing years, and its subsequent loss.

Abdominal fat tends to be located within the abdominal cavity, around the digestive organs, whereas gluteofemoral fat is subcutaneous (Figure 4). This fundamental distinction explains much of the difference in cardiovascular risk between males and females. Until recently, fat was viewed as merely a repository of excess calories, but it is now recognized as the largest endocrine organ in the body. ${ }^{32,33}$ While both visceral and subcutaneous fat are secretory (e.g. leptin), ${ }^{34}$ visceral fat is the source of inflammatory mediators such as tumour necrosis factor- $\alpha$ and interleukin- $6,{ }^{35}$ and of a novel adipocytokine called adiponectin. ${ }^{36}$ Visceral secretions are carried directly to the liver by a privileged route - the portal vein - and the liver is an important site of insulin action.

Adiponectin is unique in being negatively regulated in obesity: levels fall with increasing adiposity and seem to be inversely associated with glucose, insulin, triglyceride and BMI. ${ }^{37,38}$ Furthermore, the administration of adiponectin to animals increases insulin sensitivity. ${ }^{39}$ By accelerating tissue fat oxidation, the cytokine reduces circulating fatty acid levels and reduces the intracellular triglyceride content of liver and muscle. It also suppresses the expression of adhesion molecules in vascular epithelial cells and cytokine production from macrophages, thus down-regulating the inflammatory processes that characterize the early phases of atherosclerosis. ${ }^{40}$ Adiponectin concentrations are higher in females than in males, and they are increased by insulin sensitizing drugs such as the thiazolidinediones. ${ }^{41,42}$ Adiponectin is produced predominantly by visceral fat, ${ }^{43}$ and appears to be an important component of the final common pathway to insulin resistance.

Whether visceral fat alone causes insulin resistance is nevertheless still uncertain. It may simply coexist with some other primary process. For example, intramyocellular fat in the skeletal muscles may be important, ${ }^{44}$ or fatty infiltration of the liver could be the mechanism responsible. Nonalcoholic steatohepatitis, which commonly accompanies obesity, is associated with inflammation and may explain the disturbed hepatic enzymes and raised C-reactive protein (CRP) commonly seen in such patients. ${ }^{45}$ When an isolated raised CRP, in the apparent absence of inflammation, is found in 'screening' tests for non-specific symptoms, this may be the explanation.

The late Per Bjorntorp conceived a quite different view of insulin resistance, starting with chronic stress as the driver. ${ }^{46}$ Comparing the centripetal fat distribution and metabolic disturbances of metabolic-syndrome patients with those of Cushing's syndrome, he argued that stress may so alter the diurnal patterns of cortisol release as to create a

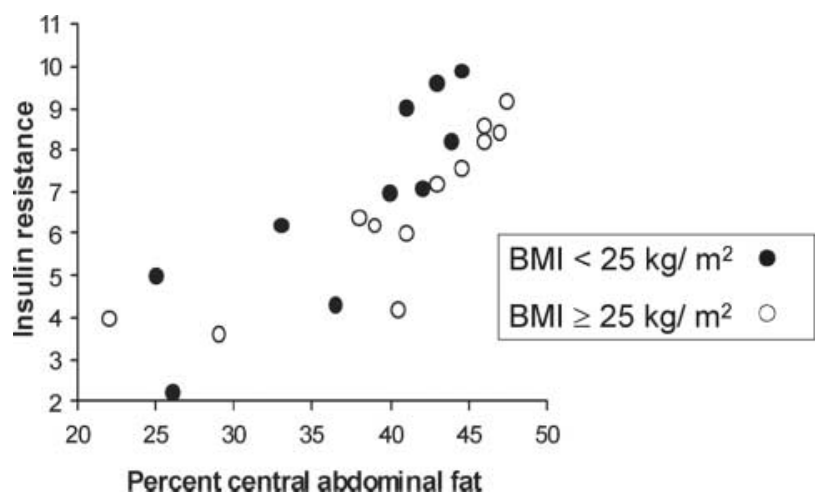

Figure 5 The relationship between visceral adiposity (\% central abdominal fat), BMI and insulin resistance. BMI does not inform on fat distribution and is a poor proxy for insulin resistance (After Ref. 47)

mildly cushingoid state. Hydrocortisone is known to stimulate appetite and to increase insulin resistance, and disturbances of corticotropin release and control are characteristic of the obese (and stressed) state. The difficulty, as so often, is in teasing out cause and effect.

CT scanning of the abdomen in the horizontal plane, and use of software to calculate per cent fat mass (adiposity), is the 'gold standard' measure of visceral adiposity but expensive to apply clinically. BMI, although a proxy for adiposity, crucially says nothing about its distribution, and several studies have underlined the importance of fat distribution in clinical assessment of metabolic risk. Carey and colleagues used dual energy X-ray absorptiometry and the hyperinsulinaemic clamp (the best measure of insulin resistance) to establish the relationship between the two in people of varying BMI (Figure 5). ${ }^{47}$ While there was a close linear correlation between per cent abdominal fat and insulin resistance, BMI was of little help in distinguishing those with high from those with low insulin resistance. Indeed, some of those with the highest insulin resistance (and highest visceral fat mass) had normal BMI, and some of those with the lowest were obese. This study identifies very clearly the clinical importance of the distinction between fat mass and fat distribution. Someone of relatively low BMI may nevertheless carry most of what little fat they have in the abdomen (extreme 'apple', sometimes referred to as the 'obese non-obese'), while a person of high BMI, officially obese, may carry very little visceral fat (extreme 'pear').

Zavaroni and his colleagues used CT to determine visceral adiposity in healthy factory workers, this time incorporating a fasting blood sample for lipids and the insulin response to glucose as a measure of insulin resistance. ${ }^{48}$ Two groups were matched exactly for age (mean 39 years) and for BMI (mean 24.7), but differed in per cent body fat that was abdominal- those below the median, and those above. The difference in metabolic status was striking (Box 1), with significantly higher insulin 
Box 1 The metabolic status of two groups of men matched for age and BMI, but of different fat distribution (After Ref. 48)

\begin{tabular}{|lcc|}
\hline & \multicolumn{2}{c|}{ Visceral fat } \\
Age & Low & High \\
BMI & 39 & 39 \\
Insulin 1h & 24.7 & 24.7 \\
Glucose 1 h & 35 & 94 \\
Triglycerides & 94 & 110 \\
Cholesterol & 1.2 & 1.7 \\
Blood pressure systolic & 4.8 & 5.1 \\
\multicolumn{1}{c}{ diastolic } & 119 & 126 \\
\hline
\end{tabular}

resistance and cardiovascular risk in the group whose body fat was predominantly visceral.

The combination of wide girth as a proxy for visceral obesity and raised triglycerides to indicate its metabolic impact has led to the notion of the 'hypertriglyceridaemic waist'. In a useful review of the concept, Despres and colleagues report that the combination of a waist circumference greater than $90 \mathrm{~cm}$ and a fasting triglyceride level greater than $2.2 \mathrm{mmol} / \mathrm{L}$ places men in the top quartile of coronary risk. ${ }^{49}$ This approach may be simpler than the Framingham risk calculator, applies to contemporary data (the Framingham cohort was recruited more than 40 years ago) and uses an index of the metabolic syndrome (triglyceride) that is seldom raised on its own. A tape measure around the waist is a reliable surrogate for visceral fat mass, ${ }^{50}$ and waist alone is probably a better measure than the waist-hip ratio, for which variable pelvic width is a confounder. ${ }^{51}$

\section{INSULIN RESISTANCE IS A METABOLIC RISK EVEN IN CHILDREN}

Type 2 diabetes, which a generation ago was referred to as 'adult-onset', 'late-onset' or 'maturity-onset', is now affecting adolescents and children. ${ }^{52,53}$ Children are crossing weight centiles faster than any other age group and over a quarter are now overweight at school entry. ${ }^{26}$

Type 2 diabetes is the outcome of a process, not the process itself. The process is that of insulin resistance and, given our understanding that clinical diabetes is preceded by a symptom-free period of rising insulin resistance, there is mounting interest in how early the process really begins. For more than a decade, the published work has dwelt on poor gestational nutrition - for which low birthweight is a proxy - as the factor principally responsible for programming metabolic disturbances later in life. ${ }^{54}$ This was the basis for the 'Barker hypothesis' (thrifty genotype hypothesis) for insulin resistance later in life. ${ }^{55}$ However, hypothesis to the insulin resistance that now pervades the industrialized world. The data largely relate to cohorts born in the first half of the 20th century, some of them before the First World War. The low birthweights of historical cohorts are no longer common in the industrialized world, while the metabolic disturbances attributed to them, such as diabetes and cardiovascular disease, are increasing. A new paradigm is needed to reconcile rising insulin resistance with rising - not falling - birthweight.

The 20th century saw unprecedented changes in western lifestyle and quality of obstetric care, and low birthweight has been replaced by a progressive rise in postnatal weight. Across the century, there were many who were subject to both poor maternal nutrition (low birthweight) and excess nutrition later in life (high current weight). Although a contributor, low birthweight may nevertheless have received undue emphasis, ${ }^{56}$ and excess weight acquired after birth (centile crossing) appears now to be the more important factor. ${ }^{57}$ What still remains unclear is the relative importance of the factors that lead to insulin resistance in children - genetics, maternal weight/nutrition/glycaemia, infant weight gain, fat patterning in childhood, physical activity, food choice.

\section{METABOLIC SYNDROME DOES NOT EXCLUDE TYPE 1 DIABETES}

However much stress is placed upon the loop that controls blood glucose, diabetes does not develop until the beta cells are no longer able to deliver sufficient insulin. Diabetes, of whatever kind, is ultimately a disorder of beta cell insufficiency. While the world has focused on the exponential rise in type 2 diabetes associated with excess weight gain and insulin resistance, less attention has been paid to a parallel rise in the incidence of type 1 diabetes. ${ }^{58}$ A unifying concept, the 'accelerator hypothesis', attempts to explain this observation. ${ }^{59}$ It proposes that type 1 and type 2 diabetes are the same disorder of insulin resistance, set against different genetic backgrounds. Those who develop type 1 diabetes are growing up in the same obesigenic environment as the remainder of societyindeed, they are heavier as toddlers than those who do not. ${ }^{60,61}$ Insulin resistance leads to metabolic upregulation and increased immunogenicity of the beta cell. It is the increased immunogenicity, the hypothesis argues, that accelerates immune-mediated beta cell death in those with a genetically more intense immune response. Given a range of genetically determined immune responsiveness in the population and progressively rising immunogenicity of the beta cell mediated by insulin resistance, the hypothesis predicts an increasing prevalence of type 1 diabetes, an earlier age at presentation as the process that causes it is accelerated, and the involvement of progressively lower risk 
genotypes. Ultimately, the population at large might be at risk from an immune response to the beta cell if the drive from insulin resistance became sufficiently widespread. Two independent studies have shown that type 1 diabetes presents not just more frequently but also earlier in heavier children (true acceleration), ${ }^{62,63}$ the recruitment of lower risk genotypes has recently been reported, ${ }^{64}$ and teenagers presenting with type 2 diabetes can be seropositive for isletrelated autoantibodies. ${ }^{65,66}$ Insulin resistance is increasingly viewed as a pro-inflammatory state, ${ }^{67}$ and the accelerator hypothesis draws together both types of diabetes into a single inflammatory entity differing only in its tempo of development. The practical implication of the hypothesis is that type 1 diabetes, like type 2, may be amenable to lifestyle correction. ${ }^{68}$

It is not rare to initiate insulin treatment with 10 units per day in a young patient with type 1 diabetes only to find, when the lean adolescent becomes an obese adult, that the dose requirement is ten times greater. The type 1 patient is now as insulin resistant and hyperinsulinaemic as the type 2; only the source of the insulin is different. The value of a diagnostic label lies in guiding appropriate treatment, but the classification traditionally applied to diabetes is being stretched to its limit when the obese patient with type 1 diabetes acquires the risk factors for cardiovascular disease normally attributed to type 2 . His health risks derive mostly from insulin resistance, and his management needs are arguably more metabolic than glycaemic.

\section{THE KEY TO MANAGEMENT OF THE METABOLIC SYNDROME IS WEIGHT REDUCTION}

Reducing blood glucose by addressing insulin resistance will benefit every spoke on the metabolic wheel. The sequence is crucial, and has important implications for management. The mortality of type 2 diabetes is largely macrovascular and related to dyslipidaemia (some have sought to label the condition 'diabetes lipidus' in recognition of the fact ${ }^{69}$ ). More than half of all hypertension is attributable to insulin resistance, and hypertension is a major contributor to the arteriopathy of diabetes. Guidelines from the UK's National Institute for Clinical Excellence are currently 'glucocentric'. They view type 2 diabetes essentially as a disease of raised blood sugar, the primary aim being to lower HbAc1. They recommend beta cell stimulators (sulphonylureas) as first-line agents in those who are not 'overweight', ${ }^{70}$ implying that type 2 diabetes in those whose BMI is $<25 \mathrm{~kg} / \mathrm{m}^{2}$ may not be related to insulin resistance. The data from Carey and Zavaroni cited earlier, however, suggest that BMI is a poor indicator of insulin resistance, and people with a BMI of $25 \mathrm{~kg} / \mathrm{m}^{2}$ already have a five-fold increased population risk of diabetes. ${ }^{10}$ High blood sugars are important to the development of microvascular disease, but sulphonylureas will raise rather than reduce insulin levels and are, in any case, of only temporary benefit because they quickly exhaust the beta cells. ${ }^{71}$ Predictably perhaps, hypertension in type 2 diabetes does not improve with further stimulation of the beta cell, while it falls in response to insulinlowering strategies such as weight loss, ${ }^{72}$ physical activity ${ }^{73}$ and insulin-sensitizing agents. ${ }^{74}$

As the management of diabetes is traditionally aimed at individual spokes of the wheel rather than at the hub that drives them, patients frequently receive multiple treatments individually destined to reduce blood pressure, blood sugar, blood cholesterol, blood coagulability and weight. It must be assumed that multiple drug interventions are advised because good-quality evidence for alternative approaches is limited. Two large studies have nevertheless shown how effective lifestyle intervention can be ${ }^{75,76}$ - though whether at greater or lesser cost than polypharmacy is uncertain. Another reason for the piecemeal approaches may be the traditional organization of specialist clinics - weight management, hypertension, infertility, diabetes, lipid-at different times, in different places and under different clinicians. Perhaps an insulin resistance clinic (the 'metabolic clinic'), to manage the cause underlying all of these disorders, would offer focus, efficiency and better allocation of funds.

Weight gain and insulin resistance are the principal cause of metabolic syndrome, and weight loss should be the first line of management, with all the dietetic and psychology skills at hand to achieve it. Paradoxically, dietetics is often the most difficult service in the National Health Service to finance for weight management. Exercise reduces insulin resistance independently of its action on body weight, ${ }^{77}$ and this is important, but physical activity is effective only for as long as it lasts, and is less efficient in achieving weight loss than calorie reduction. Some 70$75 \%$ of energy expenditure is obligatory in the form of resting energy requirements, so that a doubling of physical activity does not double energy expenditure. Halving food intake will necessarily halve calorie intake, and portion size is possibly the most important modifiable factor in the management of obesity.

Two classes of insulin-sensitizing medication are available. Metformin has been available for 50 years or more and, strictly speaking, reduces hepatic glucose release rather than insulin resistance. ${ }^{78}$ The thiazolidinedione drugs stimulate peroxisome proliferator-activated receptors, and act quite differently by controlling the genes involved in fatty acid metabolism. ${ }^{79}$ The obese patient with type 1 diabetes is deficient in endogenous insulin and resistant to exogenous insulin. It is both rational and effective to reduce this patient's insulin needs with insulin sensitizing drugs. Blood glucose control becomes easier and, more importantly, insulin levels fall. ${ }^{80}$ 
Metabolic dysovulation is recognized increasingly as a disorder of insulin resistance, ${ }^{81}$ and affected women are increasingly asking the medical profession to prescribe insulin sensitizers to assist conception. ${ }^{82}$ What cannot be obtained through the doctor is often procured from the internet. Once pregnant, however, these women will understandably abandon the medication and perhaps unwittingly embark on a pregnancy that is high-risk for both mother and child. High insulin resistance is associated with an increased risk to the mother of hypertension, gestational diabetes, pre-eclampsia and caesarean section. The fetus is exposed to developmental defects, macrosomia, pre-eclampsia and possibly metabolic disease later in life. Studies in Pima Indians suggest that those born after a mother becomes diabetic have a greater risk of weight gain and diabetes than those born before maternal development of diabetes. ${ }^{83}$ These are important considerations in view of the ready availability of metformin and the glitazones.

\section{CONCLUSION}

Metabolic syndrome has immense implications for national budgets, because its macrovascular complications are chronic and expensive to manage. They cause loss of productivity and seriously affect wellbeing and selffulfilment. It is a central issue in public health, and the politics of coping with it are difficult and complex. One thing is certain: our current understanding of metabolic syndrome came from painstaking research, and our ability to deal with it will only come from more of the same. Fivea-day fruit campaigns and break-time fruit for children for children are not enough: a government campaign for awareness at least as powerful as the anti-AIDS campaign of the 1980s is needed to shift public attitudes and behaviour.

\section{REFERENCES}

1 Reaven GM. The role of insulin resistance in human disease. Diabetes 1988;37:1595-1607

2 Seidell JC, Flegal KM. Assessing obesity: classification and epidemiology. Br Med Bull 1997;53:238-52

3 Prentice AM. Epidemiology and health risks of obesity. Topical Endocrinol 1997;6:2-4

4 Quetelet MA. A Treatise on Man and the Development of his Faculties. Edinburgh: Chambers, 1842:63-7

5 Loutan L, Lamotte JM. Seasonal variations in nutrition among a group of nomadic pastoralists in Niger. Lancet 1984;i:945-7

6 Zimmet P. Globalization, coca-colonization and the chronic disease epidemic: can the Doomsday scenario be averted? J Intern Med 2000;247:301-10

7 Illich I. Medical Nemesis. Lancet 1974;i:918-21

8 Shakespeare W. Henry IV, Part I, Act II, scene iv

9 Britz B, Siegfried W, Ziegler A, et al. Rates of psychiatric disorders in a clinical study group of adolescents with extreme obesity and in obese adolescents ascertained via a population based study. Int J Obesity Rel Metabol Disord 2000; 24:1707-14
10 Colditz GA, Willett WC, Rotnitzky A, Manson JE. Weight gain as a risk factor for clinical diabetes mellitus in women. Ann Intern Med 1995;122:481-6

11 Chan JM, Rimm EB, Colditz GA, Stampfer MJ, Willett WC. Obesity, fat distribution, and weight gain as risk factors for clinical diabetes in men. Diabetes Care 1994;17:961-9

12 Wilkin TJ. Endocrine feedback control in health and disease. In: Bittar EE, Bittar N, eds. The Principles of Medical Biology. Greenwich, CT: JAI Press, 1998, 1-28

13 Himsworth HP. Diabetes: its differentiation into insulin sensitive and insulin insensitive. Lancet 1936;i:127-30

14 Day D. Population-based screening with the Coronary Heart Disease Risk Factor Calculator. Adv Ther 2001;18:21-32

15 Bonora E, Kiechl S, Willeit J, et al. Prevalence of insulin resistance in metabolic disorders: the Bruneck Study. Diabetes 1998;47:1643-9

16 Austin MA, King MC, Vranizan KM, Krauss RM. Atherogenic lipoprotein phenotype. A proposed genetic marker for coronary heart disease risk. Circulation 1990;82:495-506

17 Enzi G, Busetto L, Carraro R. Association of multiple risk factors for cardiovascular disease and visceral obesity. A deadly quartet or sextet? In: Ditshunheit H, et al., eds. Obesity in Europe. London: Libbey, 1994:411-18

18 Robinson S, Henderson AD, Gelding SV, et al. Dyslipidaemia is associated with insulin resistance in women with polycystic ovaries. Clin Endocrinol 1996;44:277-84

19 Agarwal SK, Judd HL, Magoffin DA. A mechanism for the suppression of estrogen production in polycystic ovary syndrome. J Clin Endocrinol Metab 1996;81:3686-91

20 Laitinen J, Taponen S, Martikainen H, et al. Body size from birth to adulthood as a predictor of self-reported polycystic ovary syndrome symptoms. Int J Obes Relat Metab Disord 2003;27:710-5

21 Christian RC, Dumesic DA, Behrenbeck T, Oberg AL, Sheedy PF 2nd, Fitzpatrick LA. Prevalence and predictors of coronary artery calcification in women with polycystic ovary syndrome. $J$ Clin Endocrinol Metab 2003;88:2562-8

22 Asuncion M, Calvo RM, San Millan JL, Sancho J, Avila S, EscobarMorreale HF. A prospective study of the prevalence of the polycystic ovary syndrome in unselected Caucasian women from Spain. $J$ Clin Endocrinol Metab 2000;85:2434-8

23 Azziz R, Woods KS, Reyna R, Key TJ, Knochenhauer ES, Yildiz BO. The prevalence and features of the polycystic ovary syndrome in an unselected population. J Clin Endocrinol Metab 2004;89:2745-9

24 Seely EW, Solomon CG. Insulin resistance and its potential role in pregnancy-induced hypertension. J Clin Endocrinol Metab 2003;88: 2393-8

25 Chang CK, Ulrich CM. Hyperinsulinaemia and hyperglycaemia: possible risk factors of colorectal cancer among diabetic patients. Diabetologia 2003;46:595-607.

26 Furberg AS, Veierod MB, Wilsgaard T, Bernstein L, Thune I. Serum high-density lipoprotein cholesterol, metabolic profile, and breast cancer risk. J Natl Cancer Inst 2004;96:1152-60

27 Norman RJ, McVeigh E. Polycystic ovary syndrome and implications for the menopause. Climacteric 1999;2:141-3

28 McElroy SL, Kotwal R, Malhotra S, Nelson EB, Keck PE, Nemeroff $\mathrm{CB}$. Are mood disorders and obesity related? A review for the mental health professional. J Clin Psychiatry 2004;65:634-51

29 Vague $\mathrm{J}$. The degree of masculine differentiation in obesity as a factor determining predisposition to diabetes, atherosclerosis, gout and uric calculous disease. Am J Clin Nutr 1956;4:20-34

30 Voss LD, Metcalf BS, Jeffery AN, et al. Preventable factors in childhood that lead to insulin resistance, diabetes mellitus and the metabolic syndrome: the EarlyBird Diabetes Study (1). J Pediatr Endocr Metab 2003;16:1211-24

31 Gambacciani M, Ciaponi M, Cappagli B, Benussi C, De Simone L, Genazzani AR. Climacteric modifications in body weight and fat tissue distribution. Climacteric 1999;2:37-44 
32 Kershaw EE, Flier JS. Adipose tissue as an endocrine organ. $J$ Clin Endocrinol Metab 2004;89:2548-56

33 Pantanetti P, Garrapa GG, Mantero F, Boscaro M, Faloia E, Venarucci D. Adipose tissue as an endocrine organ? A review of recent data related to cardiovascular complications of endocrine dysfunctions. Clin Exp Hypertens 2004;26:387-98

34 Correia ML, Haynes WG. Leptin, obesity and cardiovascular disease. Curr Opin Nephrol Hypertens 2004;13:215-23

35 Meier U, Gressner AM. Endocrine regulation of energy metabolism: review of pathobiochemical and clinical chemical aspects of leptin, ghrelin, adiponectin, and resistin. Clin Chem 2004;50:1511-25

36 Diez JJ, Iglesis P. The role of the novel adipocyte-derived hormone adiponectin in human disease. Eur J Endocrinology 2003;148:293-300

37 Arita Y, Kihara S, Ouchi N, et al. Paradoxical decrease of an adiposespecific protein, adiponectin, in obesity. Biochem Biophys Res Commun 1999;257:79-83

38 Stefan N, Bunt JC, Salbe AD, Funahashi T, Matsuzawa Y, Tataranni PA. Plasma adiponectin concentrations in children: relationships with obesity and insulinemia. J Clin Endocrinol Metab 2002;87:4652-6

39 Fruebis J, Tsao TS, Javorschi S, et al. Proteolytic cleavage product of $30-\mathrm{kDa}$ adipocyte complement-related protein increases fatty acid oxidation in muscle and causes weight loss in mice. Proc Natl Acad Sci USA 2001;98:2005-10

40 Ouchi N, Kihara S, Arita Y, et al. Adipocyte-derived plasma protein, adiponectin, suppresses lipid accumulation and class A scavenger receptor expression in human monocyte-derived macrophages. Circulation 2001;103:1057-63

41 Yang WS, Jeng CY, Wu TJ, et al. Synthetic peroxisome proliferatoractivated receptor-gamma agonist, rosiglitazone, increases plasma levels of adiponectin in type 2 diabetic patients. Diabetes Care 2002;25:376-80

42 Hirose H, Kawai T, Yamamoto Y, et al. Effects of pioglitazone on metabolic parameters, body fat distribution, and serum adiponectin levels in Japanese male patients with type 2 diabetes. Metabolism 2002;51:314-7

43 Park KG, Park KS, Kim MJ, et al. Relationship between serum adiponectin and leptin concentrations and body fat distribution. Diabetes Res Clin Pract 2004;63:135-42

44 Machann J, Haring H, Schick F, Stumvoll M. Intramyocellular lipids and insulin resistance. Diabetes Obes Metab 2004;6:239-48

45 Brunt EM. Nonalcoholic steatohepatitis. Semin Liver Dis 2004;24:3-20

46 Bjorntorp P, Rosmond R. The metabolic syndrome-a neuroendocrine disorder? Br J Nutr 2000;83 Suppl 1:S49-57

47 Carey DG, Jenkins AB, Campbell LV, Freund J, Chisholm DJ. Abdominal fat and insulin resistance in normal and overweight women: direct measurements reveal a strong relationship in subjects at both low and high risk of NIDDM. Diabetes 1996;45: 633-8

48 Zavaroni I, Bonora E, Pagliara M, et al. Risk factors for coronary artery disease in healthy persons with hyperinsulinemia and normal glucose tolerance. N Engl J Med 1989;320:702-6

49 Despres JP, Lemieux I, Prud'homme D. Treatment of obesity: need to focus on high risk abdominally obese patients. BMJ 2001;322:716-20

50 Pouliot MC, Després JP, Lemieux S, et al. Waist circumference and abdominal sagittal diameter: best simple anthropometric indexes of abdominal visceral adipose tissue accumulation and related cardiovascular risk in men and women. Am J Cardiol 1994;73: $460-8$

51 Lemieux S, Prud'homme D, Tremblay A, Bouchard C, Després JP. Anthropometric correlates to changes in visceral adipose tissue over 7 years in women. Int J Obes Relat Metab Disord 1996;20:618-24

52 Drake AJ, Smith A, Betts PR, Crowne EC, Shield JP. Type 2 diabetes in obese white children. Arch Dis Child 2002;86:207-8

53 Aye T, Levitsky LL.Type 2 diabetes: an epidemic disease in childhood. Curr Opin Pediatr 2003;15:411-15
54 Hales CN, Barker DJ, Clark PM, et al. Fetal and infant growth and impaired glucose tolerance at age 64. BMJ 1991;303:019-22

55 Barker DJ. In utero programming of chronic disease. Clin Sci (Lond) 1998;95:115-28

56 Lucas A, Fewtrell MS, Cole TJ. Fetal origins of adult disease - the hypothesis revisited. BMJ 1999;319:245-9

57 Wilkin TJ, Metcalf BS, Murphy MJ, Kirkby J, Jeffery AN, Voss LD. The relative contributions of birth weight, weight change, and current weight to insulin resistance in contemporary 5-year-olds: the EarlyBird Study. Diabetes 2002;51:3468-72

58 Onkamo P, Vaananen S, Karvonen M, Tuomilehto J. Worldwide increase of type 1 diabetes - analysis of the data on published incidence trends. Diabetologia 1999;42:1395-403

59 Wilkin TJ. The Accelerator Hypothesis: weight gain as the missing link between type I and type II diabetes. Diabetologia 2001;44:914-22

60 Baum JD, Ounsted M, Smith MA. Weight gain in infancy and subsequent development of diabetes mellitus in childhood. Lancet 1975;ii:866

61 Hypponen E, Virtanen SM, Kenward MG, Knip M, Akerblom HK. Obesity, increased linear growth, and risk of type 1 diabetes in children. Childhood Diabetes in Finland Study Group. Diabetes Care 2000;23:1755-60

62 Kibirige M, Metcalf BS, Mallam K, Renuka R, Wilkin TJ. Testing the Accelerator Hypothesis (1): The relationship between body mass and age at diagnosis of type 1 diabetes. Diabetes Care 2003;26: 2865-70

63 Betts $\mathrm{P}$, Mulligan J, Ward P, Smith B, WilkinTJ. Increasing body weight predicts the earlier onset of insulin dependant diabetes in childhood: testing the 'Accelerator Hypothesis' (2). Diabetic Med (in press)

64 Hermann R, Knip M, Veijola R, et al. Temporal changes in the frequencies of HLA genotypes in patients with type 1 diabetesindication of an increased environmental pressure? Diabetologia 2003;46:420-5

65 Hathout EH, Thomas W, El-Shahawy M, Nahab F, Mace JW. Diabetic autoimmune markers in children and adolescents with type 2 diabetes. Pediatrics 2001;107:E102

66 Umpaichitra V, Banerji MA, Castells S. Autoantibodies in children with type 2 diabetes mellitus. J Pediatr Endocrinol Metab 2002;15 suppl $1: 525-30$

67 Dandona P, Aljada A, Bandyopadhyay A. Inflammation: the link between insulin resistance, obesity and diabetes. Trends Immunol 2004;25:4-7

68 Wilkin T, Ludvigsson J, Greenbaum C, Palmer J, Becker D, Bruining J. Future intervention trials in type 1 diabetes. Diabetes Care 2004;27:996-7

69 Shafrir E, Raz I. Diabetes: mellitus or lipidus? Diabetologia 2003;46:433-40

70 [http://www.nice.org.uk/pdf/NICE_INHERITEG_guidelines.pdf]

71 Matthews DR, Cull CA, Stratton IM, Holman RR, Turner RC.UKPDS 26: sulphonylurea failure in non-insulin-dependent diabetic patients over six years. UK Prospective Diabetes Study (UKPDS) Group. Diabet Med 1998;15:297-303

72 Sharma AM, Golay A. Effect of orlistat-induced weight loss on blood pressure and heart rate in obese patients with hypertension. J Hypertens 2002;20:1873-8

73 Fleischmann EH, Friedrich A, Danzer E, Gallert K, Walter H, Schmieder RE. Intensive training of patients with hypertension is effective in modifying lifestyle risk factors. J Hum Hypertens 2004; 18:127-31

74 Shargorodsky M, Wainstein J, Gavish D, et al. Treatment with rosiglitazone reduces hyperinsulinemia and improves arterial elasticity in patients with type 2 diabetes mellitus. Am J Hypertens 2003;16: 617-22

75 Tuomilehto J, Lindstrom J, Eriksson JG, et al. Prevention of type 2 diabetes mellitus by changes in lifestyle among subjects with impaired glucose tolerance. N Engl J Med 2001;344:1343-50 
76 Knowler WC, Barrett-Connor E, Fowler SE, et al. Diabetes Prevention Program Research Group. Reduction in the incidence of type 2 diabetes with lifestyle intervention or metformin. $N$ Engl $J$ Med 2002;346:393-403

77 Cox KL, Burke V, Morton AR, Beilin LJ, Puddey IB. Independent and additive effects of energy restriction and exercise on glucose and insulin concentrations in sedentary overweight men. Am J Clin Nutr 2004;80:308-16

78 Hundal RS, Inzucchi SE. Metformin: new understandings, new uses. Drugs 2003;63:1879-94

79 Camejo G, Ljung B, Oakes N. Pharmacological treatment of insulin resistance in obesity. Nutr Metab Cardiovasc Dis $2001 ; 11: 275-84$
80 Sarnblad S, Kroon M, Aman J. Metformin as additional therapy in adolescents with poorly controlled type 1 diabetes: randomised placebo-controlled trial with aspects on insulin sensitivity. Eur $J$ Endocrinol 2003;149:323-9

81 Vrbikova J, Cibula D, Dvorakova K, et al. Insulin sensitivity in women with polycystic ovary syndrome. J Clin Endocrinol Metab 2004;89: 2942-5

82 Ben-Haroush A, Yogev Y, Fisch B. Insulin resistance and metformin in polycystic ovary syndrome. Eur $J$ Obstet Gynecol Reprod Biol 2004;115:125-33

83 Dabelea D, Pettitt DJ. Intrauterine diabetic environment confers risks for type 2 diabetes mellitus and obesity in the offspring, in addition to genetic susceptibility. J Pediatr Endocrinol Metab 2001;14: 1085-91 